fruitful-and his examples are indeed chiefly drawn from aeronautics and textile technology. The problem is not so acuto to the academic scientist, who can usually scan the relatively few top journals in his own subject and these contain most of the best work. If the sea of the world literature is to be dredged for all relevant papers, a great deal of rubbish will come to the surface-the indexer cannot be a judge as well. This sceptical view is, of course, an extreme ono. But scientists should be made aware of the problems involved and be sure that present bibliographic aids (scarcoly mentioned in this book) have failed before they allow librarians into the driving-seat of a computer.

P. C. WrLIrams

\section{ENGINEERING APPLICATIONS OF RUBBERS}

\section{Rubber in Engineering Practice}

By A. B. Davey and A. R. Payne. Pp. $x+501$. (London: MacLaren and Sons, Ltd.; New York: Palmerton Publishing Co., Inc., 1964.) $90 s$.

$\mathrm{P}$ RHAPS the strongest impression gained on perusing Rubber in Engineering Practice is of the remarkable variety and range of what may be broadly called the 'engineering applications' of rubbers-a term which includes not only engineering in the narrower sense, typified by engine mountings, couplings for power transmission and spring suspensions, but also such widely diverse uses as sound insulation in buildings, anti-vibration mountings for instruments, and packaging devices in sponge or other form. All these applications are dealt with in considerable detail, and while, no doubt, some selection must have been unavoidable, it is difficult to believe that any really important application has been omitted. As a source of information on what devices are available, therefore, this book is likely to be eagerly sought by engineers interested in this general field.

The book, however, is far from being a mere compilation, for in addition to its clear presentation, with a very large number of detailed drawings, of the various engineering components utilizing rubber in one form or another, it includes a genoral seientific introduction to the physical (and where necessary chemical) properties of rubbers, and the way in which these are applied in the design of engineering components. Starting from the basic types of deformation, shear, torsion and compression, it shows how these may be applied, and in many cases combined, to give a wide variety of spring characteristics to meet the many types of complex loading encountered. In addition to this, the basic mechanies of suspension systems, of the transmission and absorption of vibrations, including resonance phenomena, and, in general, of the response of coupled systems to oscillatory disturbances, is discussed. Some of this material has already appeared in an earlier book on this subject (Engineering Design with Rubber, by Payne and Scott).

Not unnaturally, a large part of the book is taken up with engineering applications in the narrower sense, and in this Davey and Payne have drawn heavily on the industrial experience of particular firms who have specialized in the production of engineering components. Even so, the operation of the many components depictedsome of remarkable ingenuity and subtlety of design-is fully discussed in the light of the scientific principles expounded in the first section, and good and bad features of design are brought out.

While rubber components such as shock absorbers and vibration insulators, particularly in connexion with transport vehicles, have been with us for a long time, the growing field of application in civil engineering is of more recont development. Surprising as it may appoar at first sight, the use of rubber as a support for bridges is an example of an application in which this material has a clear technical advantage over alternative systems.
It is interesting to learn that such bridges as the Tancarville bridge across the Seine $(960 \mathrm{~m})$ and the St. Lawrence Harbour bridge, Canada $(3 \mathrm{~km})$, are supported on rubber, and it is stated that not one of the many natural rubber bridge bearings which have been installed during the past 10 years, so far as is known, has failed or shown signs of failure.

The least satisfying part of the book is probably the introductory part, in which the physical properties of rubbers are discussed. The impression is given that too much ground is being covered, and the presentation is not always as clearly thought out, or as preciso, as might be desired. For example, Fig. 3.2 gives the erroneous impression that the stress-strain relations for rubber are linear for compressions up to 40 per cent, and for extensions up to 25 per cent (though the text makes it clear that this is not so). Again, there is confusion over the stress-strain relations dorived from the statistical theory; Kuhn did not derive equation (3.2), and in the reference to his paper dealing with the properties of a bulk rubber (dated 1936, not 1934) it is not true to say that he considered only a single moleculo; though not explicitly dofining a cross-linked network of molecules, he adopted a simplified model in which one-third of the molecules were oriented parallel to each of the three co-ordinate axes, which, as has since been shown, is basically equivalent to the more general network treatment. Readers who are concerned with the basic physical properties of rubbers will need to supplement this account with additional reading.

Apart from this, the book succeeds in its purpose of presenting a broad general survey of the whole subject of the engineering aspects of rubbers, and can be confidently recommended.

L. R. G. Treloar

\section{FAST BIOCHEMICAL REACTIONS}

\section{Rapid Mixing and Sampling Techniques in Biochemistry} Proceedings of the First International Colloquium on Rapid Mixing and Sampling Techniques Applicable to the Study of Biochemical Reactions, Philadelphia, July 23-24, 1964. Edited by Britton Chance, Rudolf H. Eisenhardt, Quentin H. Gibson and K. Karl Longberg-Holm. Pp. xii + 400. (New York and London: Academic Press, 1964.) 72s. DHYSICAL chemists have long been interested in rapid reactions, and $\mathrm{E}$. $\mathrm{F}$. Caldin has recently written a book concerned with their study in solution ${ }^{1}$. Biochemists who work with bactoria also know that these cells catalyse quite fast reactions and that Macbeth might well have been making reference to experiments with such systems when he said": "If it were done when 'tis done, then 'twere well it were done quickly"; for if it is desired to show that, for example, ${ }^{14} \mathrm{C}$-acetate is converted initially into malate by a growing culture of Pseudomonas then all the samples should be taken within the first half-minute of the start of the experiment ${ }^{3}$. One of the contributors to this symposium is J. A. Bassham, whose work with M. Calvin and others revealed the pathway of carbon in photosynthesis by a technique that involved rapid sampling of algal cultures; and with $\mathbf{M}$. Kirk this author describes an application of this technique to follow changes in the photosynthetic carbon reduction cycle that occur when inhibitors aro added. However, most of the other authors deal with methods more suited to the study of rapid reactions catalysed by onzymes in isolation, or to the rapid arrest of metabolism in muscle or liver. In general the biochemical results obtained are not discussod: the emphasis throughout is placed on the design of the apparatus used. Theoretical principles involved in the construction of apparatus are given in appendixes: thus, H. K. Wiskind gives examples of the application of fluid dynamics to the development of rapid mixing techniques, sinco one problem in the study of rapidly reacting compounds is clearly that of mixing them fast onough. 